\section{Funding: income criterion would hit postdoc careers}

SIR - I was surprised to read your Editorial "Brown's budget briefing" (Nature 440, 581; 2006), backing the UK government's recent suggestion that external research income should replace much of the current Research Assessment Exercise (RAE). An obvious problem with this proposal is that the RAE affects not only the funding of individual departments, but their hiring and firing policy too. Why would departments ever appoint postdoctoral researchers to junior lectureships if the RAE-replacement was a metric based on external research income? Whatever the quality of their research up to that point, postdocs only become eligible to be principal investigator on research council grants when in a permanent post. An already difficult career step for many postdocs would only get harder.

Phil Bland

Department of Earth Science and Engineering, Royal School of Mines, Imperial College London, South Kensington Campus, London SW7 2AZ, UK

\section{Funding: proposals ignore mentoring and teaching}

SIR - Christopher Exley, in Correspondence ( ${ }^{\infty}$ Funding should recognize outcome, not income ${ }^{x}$ Nature 440,1112; 2006), rightly criticizes the proposal that past research income should be used to assign future funding. But he falls back on the equally simplistic idea that "the only significant research outcome is the science and, primarily, its communication through publication.

Mentoring and teaching, both of students and the public, have long been the poor relations of publication and funding in the eyes of many researchers. For example, the current strike by UK university lecturers involves the suspension of teaching duties, rather than the suspension of either grant applications or manuscript submissions. Although a boycott of grant applications would, arguably, hit institutes harder than a teaching boycott, lecturers can suspend lecturing at minimal cost to themselves because academic preferment is rarely dependent on the ability to educate.

Given the UK's shortage of science and engineering graduates, this underappreciation of education is a terrible and preventable waste. But there is little incentive to mentor in the current UK system and few people, scientists included, do something for nothing. It would be an opportunity missed if more emphasis were not placed on developing the potential of young scientists for the next Research Assessment Exercise.
How many scientific outcomes are more significant than inspiring and training the generation which is to replace us? John Bothwell

Marine Biological Association of the UK, The Laboratory, Plymouth PL1 2PB, UK

\section{Funding: income is already dependent on outcome}

SIR - Christopher Exley, in Correspondence ("Funding should recognize outcome, not income ${ }^{n}$ Nature 440, 1112; 2006), criticizes the use of research income as a metric of science somewhat unjustly. As someone involved in the review of research grants in the United Kingdom, I have found that research income - at least in the case of government research councils, and probably also for charities and industry - is highly dependent on previous and proposed research outcomes. Funding proposals require a brief biography listing previous outcomes as well as a list of expected outcomes and dissemination strategies, both of which reviewers are asked to assess.

Perhaps this is why previous runnings of the Research Assessment Exercise (RAE) have shown a strong correlation between research income and RAE score, at least in disciplines such as science, which require substantial grant income. Although this correlation is not perfect, the time cost to the UK research community of conducting the RAE is not justified by the difference. Further, interdisciplinary researchers who contribute to more than one literature will no longer be disadvantaged.

The main concern is that comparison must be done on a sufficiently narrow scope so that different branches of disciplines do not lose political clout if their research is relatively inexpensive. For example, if comparisons were made at the full departmental level, biology departments would be rewarded for dumping their field researchers in favour of molecular or cell biologists, and computer science departments for dumping theory of computation in favour of robotics. Joanna Bryson Department of Computer Science, University of Bath, Bath BA2 7AY, UK

\section{Technology transfer is all about bringing in money}

SIR - Your Editorial about technologytransfer offices, "More than the money" (Nature 440, 845-846; 2006), is, in my opinion, dangerous and wrong.

It is dangerous because, at a time when governments are investing in science with the reasonable hope that new knowledge can lead to economic advantage, it is ammunition for critics to suggest otherwise.

It is wrong both in principle and in practice. The chemistry department at Oxford has contributed some $£ 80$ million (US\$150 million) to the central university over the past ten years. Actual realized gains from the departmental spin-offs come to more than $£ 40$ million, with about $£ 20$ million of unrealized gains in quoted companies and a further batch of holdings in private companies. Of these, one has raised several millions in a pre-flotation round, another has a multimillion-pound contract with a major pharmaceutical company, and a third has a huge European Union grant. This has been achieved without any pressure on academics to modify their research or even to push people into commercialization.

Many technology-transfer offices are frankly not very good. They should not be allowed to pretend that bringing money in to their universities is not one of their major roles.

\section{W. Graham Richards}

Central Chemistry Laboratory, University of Oxford, South Parks Road, Oxford OX13QH, UK

\section{Debye's wooden response undercut Nazi orders}

SIR - I read with chagrin your News in Brief story "Dutch universities ditch reported Nazi collaborator" (Nature 440,139;2006), stating that two Dutch universities have rescinded the recognition previously accorded to Peter Debye. I was a junior member of his chemistry department at Cornell University and I remember two stories in particular that make it hard to believe Debye had Nazi links.

Debye told us about one of the buildings at the Kaiser Wilhelm Institute for Physics, where he was director, that had the name of the previous director, Max Planck, chiselled in stone above the entrance. When ordered to erase the dedication to Planck (who had tried to help Jewish colleagues), Debye had workmen cover it with a large wooden board. That way, when visitors asked about the unseemly aberration, he would feel obliged to answer.

He also described how he was finally convinced to flee Germany when a direct order came from Hitler to put all the institute's resources into the development of the atomic bomb. Carrying only their suitcases, Debye and his wife travelled to the Netherlands, ostensibly for a lecture tour, but they never returned. Instead they went on to London and eventually to America.

Harvey Posvic

Department of Chemistry, Loyola University Chicago, 1068 West Sheridan Road, Chicago, Illinois 60626, USA 